\title{
Importance of the Epidemic Curve for Cross-country Comparison of COVID-19 Mortality: A Brief Analysis on Interpreting the Pandemic Numbers
}

\author{
Bartolomeu A Nascimento $\mathrm{Jr}^{1}$, Lorena T de Melo Rolim ${ }^{2}$, Gustavo P Fraga ${ }^{3}$, Sandro Rizoli ${ }^{4}$ \\ Keywords: Infection, Mortality, Mortality rate. \\ Palabras clave: Infecção, mortalidade, taxa de mortalidade \\ Panamerican Journal of Trauma, Critical Care \& Emergency Surgery (2020): 10.5005/jp-journals-10030-1276
}

Our planet is experiencing an unprecedented public health crisis. The ongoing COVID-19 pandemic is ubiquitously making headlines daily. Currently, 216 countries, areas, or territories have documented COVID-19 cases. Many are publicizing numbers of deaths per population by country as a measure of the "country's performance" in handling this global crisis. Indeed, death ranks are being created to ascertain a "nation's failure or success."

Due to the pandemic, the World Health Organization (WHO) has made available daily data on COVID-19 cases and mortality. ${ }^{1}$ This is extremely valuable to inform countries on the spread of the disease and its lethality. This information can guide pandemic preparedness plans across the globe. However, caution should be exercised when using such data for unadjusted cross-country comparisons, particularly on disease lethality.

Increasing death rates are naturally observed as an epidemic takes its course. The epidemic curve is a visual display of outbreak cases. ${ }^{2}$ It starts with the first confirmed case in a population. Then, it develops as an expression mainly of the incubation period, mode of transmission, and transmissibility. The number of cases and associated deaths of a disease grow exponentially on its epidemic curve.

The goal of this brief analysis is to demonstrate that mortality rates are modifiable when considering the pandemic phase of each country. In order to adjust for the epidemic curve of COVID19 in countries with higher numbers of deaths according to the WHO available data, we calculated the time elapsed between the first reported case and May 16, 2020. All countries included had a minimum of 80 days into their epidemic curve. The Netherlands had the shortest epidemic curve with 80 days. Then, this was used as the reference epidemic curve for cross-country comparison. We also reported mortality rates per 1,000,000 inhabitants.

On the WHO online dashboard, the absolute number of new deaths by country is reported daily as well as the number of cumulative deaths over the pandemic period. We included the top 10 countries with the highest cumulative numbers of deaths listed by the WHO on May 16, 2020. With 118 pandemic days, the United States had the highest absolute number of deaths for the period. Among the top 10 countries, the Netherlands reported the lowest absolute number of deaths (Table 1). However, considering the country population, the U.S. mortality dropped to $7^{\circ}$ place and Brazil had the lowest mortality rate on the rank of all countries analyzed (Table 1$)$.

When accounting for the epidemic curve, we observed additional changes on the rank of countries by mortality rates
${ }^{1}$ Diretoria, Hospital Getulio Vargas, Recife, Pernambuco, Brazil

${ }^{2}$ Medicina, Faculdade Pernambucana de Saude, Recife, Pernambuco, Brazil

${ }^{3}$ Department of Cirurgia, Unicamp, Campinas, São Paulo, Brazil

${ }^{4}$ Hamad General Hospital, Qatar

Corresponding Author: Bartolomeu A Nascimento Jr, Diretoria, Hospital Getulio Vargas, Recife, Pernambuco, Brazil, Phone: +558131845606, e-mail: Barto.NascimentoJr@outlook.com

How to cite this article: Nascimento Jr BA, de Melo Rolim LT, Fraga GP, et al. Importance of the Epidemic Curve for Cross-country Comparison of COVID-19 Mortality: A Brief Analysis on Interpreting the Pandemic Numbers. Panam J Trauma Crit Care Emerg Surg 2020;9(2):120-121.

Source of support: Nil

Conflict of interest: None

(Table 2). Interestingly, the United States had the lowest mortality rate of all countries included. Belgium appeared as the country with the highest death rate among the top 10 countries. In this new scenario, the United States had a mortality rate of approximately 14 times lower than the one seen for Belgium. Brazil, the only South America country, registered one of the lowest mortality rates, only being superior to the ones documented in the United States and Germany.

Table 1: Mortality per 1,000,000 population by country

\begin{tabular}{|c|c|c|c|c|}
\hline Country & $\begin{array}{l}\text { Population* } \\
\text { (million) }\end{array}$ & $\begin{array}{l}\text { Days of } \\
\text { pandemic }\end{array}$ & Deaths & Deaths $/ 1,000,000$ \\
\hline Belgium & $11,589,623$ & 103 & 8,959 & 773 \\
\hline Spain & $46,754,778$ & 107 & 27,459 & 587 \\
\hline Italy & $60,461,826$ & 109 & 31,610 & 523 \\
\hline $\begin{array}{l}\text { United } \\
\text { Kingdom }\end{array}$ & $67,886,011$ & 107 & 33,998 & 501 \\
\hline France & $65,273,511$ & 114 & 27,482 & 421 \\
\hline Netherlands & $17,134,872$ & 80 & 5,643 & 329 \\
\hline $\begin{array}{l}\text { United } \\
\text { States }\end{array}$ & $331,002,651$ & 118 & 83,819 & 253 \\
\hline Germany & $83,783,942$ & 110 & 7,881 & 94 \\
\hline Iran & $83,992,949$ & 88 & 6,902 & 82 \\
\hline Brazil & $212,559,417$ & 81 & 13,993 & 66 \\
\hline
\end{tabular}

*Worldometers.info/world-population/population-by-country/, accessed on May 16,2020 , at 15:00H UTC-3

() The Author(s). 2020 Open Access This article is distributed under the terms of the Creative Commons Attribution 4.0 International License (https://creativecommons. org/licenses/by-nc/4.0/), which permits unrestricted use, distribution, and non-commercial reproduction in any medium, provided you give appropriate credit to the original author(s) and the source, provide a link to the Creative Commons license, and indicate if changes were made. The Creative Commons Public Domain Dedication waiver (http://creativecommons.org/publicdomain/zero/1.0/) applies to the data made available in this article, unless otherwise stated. 
Table 2: Mortality per $1,000,000$ population adjusted for 80 -day pandemic curve by country

\begin{tabular}{lcrl}
\hline Country & $\begin{array}{l}\text { Population* } \\
\text { (million) }\end{array}$ & Deaths & Deaths/1,000,000 \\
\hline Belgium & $11,589,623$ & 6,490 & 559.9 \\
Spain & $46,754,778$ & 20,453 & 437.4 \\
Italy & $60,461,826$ & 22,747 & 376.2 \\
Netherlands & $17,134,872$ & 5,643 & 329.3 \\
France & $65,273,511$ & 14,374 & 220.2 \\
United Kingdom & $67,886,011$ & 14,576 & 214.7 \\
Iran & $83,992,949$ & 6,589 & 78.4 \\
Brazil & $212,559,417$ & 13,149 & 61.9 \\
Germany & $83,783,942$ & 3,868 & 46.2 \\
United States & $331,002,651$ & 12,740 & 38.5 \\
\hline
\end{tabular}

*Worldometers.info/world-population/population-by-country/, accessed on May 16,2020 , at 15:00H UTC-3

The lethality of a new organism during an outbreak is related to several factors. The host-pathogen interaction, which is associated with the ability of the organism to produce disease and death, is a determinant factor for mortality rates during an epidemic. The blueprint of organism infectivity in a community is also extremely relevant. Cities with high population density are particularly susceptible to airborne and contact disease dissemination. The higher the number of people who become ill simultaneously, the greater the demand on healthcare systems. The capacity of a healthcare system to cope with an increased demand during an outbreak might influence mortality rates. ${ }^{3}$ Finally, the unavailability of disease-specific treatment and lack of mitigation strategies, such as social distancing and lockdowns, play significant roles in pandemic lethality. ${ }^{4}$ Therefore, any comparison of cross-country mortality rates should consider the aforementioned factors.

In the case of the new coronavirus, it is already known its ability to disseminate through direct contact and air. Similar to any other infectious disease, it holds a predicted pattern of dissemination, disease, and complications. A median incubation period of approximately 5 days and a time up to 14 days for the onset of symptoms have been described for the COVID-19. ${ }^{5} \mathrm{~A}$ reproduction number $\left(R_{0}\right)$, which is the pathogen capacity to infect, of approximately 3 has been ascertained for the new coronavirus. ${ }^{6}$
Based on this, each infected individual is able to infect three persons. Accordingly, an exponential increase is expected during the COVID-19 epidemic curve. Based on 72,314 cases from Wuhan, it was estimated that $81 \%$ of patients are classified as mild, $14 \%$ as severe, and $5 \%$ as critical. ${ }^{7}$ Case fatality rates from 0.3 to $15 \%$ have been reported. ${ }^{8}$

In summary, our analysis emphasizes the importance of exercising caution when interpreting data on COVID-19 mortality by country. It underlines the need to account for the epidemic curve for cross-country comparison of COVID-19 mortality rates. Of note, other factors not addressed by our analysis, which might influence lethality by COVID-19, such as a country's age distribution and development status, healthcare system robustness, and mitigation measures, should also be taken into consideration. Finally, we acknowledge that testing rates, reporting delays, and underreporting might influence lethality rate numbers at a given time.

\section{References}

1. WHO Health Emergency Dashboard. WHO (COVID-19) Homepage. https://covid19.who.int/.

2. Straif-Bourgeois S, Ratard R, Kretzschmar M. Infectious disease epidemiology. handbook of epidemiology. Handbook Epidemiol 2014. 2041-2119. DOI: 10.1007/978-0-387-09834-0_34.

3. Zhang Z, Yao W, Wang Y, et al. Wuhan and Hubei COVID-19 mortality analysis reveals the critical role of timely supply of medical resources. J Infect 2020. DOI: 10.1016/j.jinf.2020.03.018.

4. Anderson RM, Heesterbeek H, Klinkenberg D, et al. How will countrybased mitigation measures influence the course of the COVID-19 epidemic? Lancet 2020;395(10228):931-934. DOI: 10.1016/S01406736(20)30567-5.

5. Lauer $\mathrm{SA}$, Grantz KH, Bi Q, et al. The incubation period of coronavirus disease 2019 (COVID-19) from Publicly reported confirmed cases: estimation and application. Ann Intern Med 2020. M20-0504. DOI: 10.7326/M20-0504.

6. Li Q, Guan X, Wu P, et al. Early transmission dynamics in Wuhan, China, of novel coronavirus-infected Pneumonia. N Engl J Med 2020;382(13):1199-1207. DOI: https://doi: 10.1056/NEJMoa2001316.

7. Wu Z, McGoogan JM. Characteristics of and important lessons from the coronavirus disease 2019 (COVID-19) outbreak in China: summary of a report of 72314 cases from the Chinese Center for Disease Control and Prevention. JAMA 2020(13). DOI: 10.1001/jama.2020.2648.

8. Rajgor DD, Lee MH, Archuleta S, et al. The many estimates of the COVID-19 case fatality rate. 2020;S1473-3099(20):30244-30249. DOI: 10.1016/S1473-3099(20)30244-9. 